ISSN 2236-0859

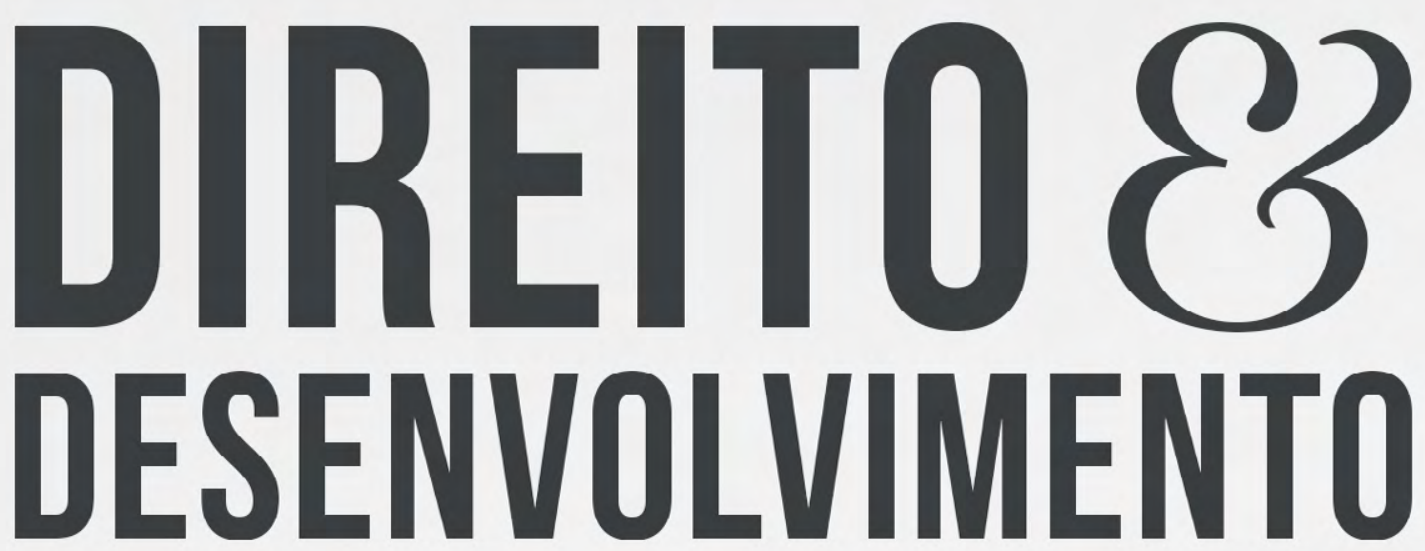

REVISTA DO PROGRAMA DE PÓS-GRADUAÇÃO EM DIREITO MESTRADO EM DIREITO E DESENVOLVIMENTO SUSTENTÁVEL

OPAPEL ESSENCIAL E FUTURISTA DA EDUCAÇÃO E DOS INVESTIMENTOS EM CIENNCIA E TECNOLOGIA NO APRIMORAMENTOE CATALISACSÃODO MODELO CHINESS DE DESENVOLVIMENTO

MAURÍCIO MURIACK DE FERNANDES PEIXOTO ARNALDO SAMPAIO DE MORAES GODOY 


\title{
O PAPEL ESSENCIAL E FUTURISTA DA EDUCAÇÃO E DOS INVESTIMENTOS EM CIÊNCIA E TECNOLOGIA NO APRIMORAMENTO E CATALISAÇÃO DO MODELO CHINÊS DE DESENVOLVIMENTO
}

\author{
THE ESSENTIAL AND FUTURISTIC ROLE OF EDUCATION AND INVESTMENT \\ IN SCIENCE AND TECHNOLOGY IN ENHANCING AND CATALYZING THE \\ CHINESE MODEL OF DEVELOPMENT
}

Recebido: 01/04/2018

Aprovado: 26/04/2018
Maurício Muriack de Fernandes Peixoto* Arnaldo Sampaio de Moraes Godoy**

RESUMO: O presente artigo tem por objetivo descrever e demonstrar de que forma a China há privilegiado o investimento em educação básica e avançada e em ciência e tecnologia como instrumentos estratégicos para alavancar a concreção do direito ao desenvolvimento. O problema que iremos pesquisar é o da imprescindibilidade da primazia aos investimentos educacionais básicos e avançados e em pesquisa tecnológica como elementos paulatinos de sustentabilidade da continuidade do progresso chinês. A metodologia que iremos adotar será a de pesquisa bibliográfica. O objeto é relevante cientificamente porque revela como a educação e a pesquisa em ciência e tecnologia se transformaram em sustentáculos insubstituíveis para o paradigmático progresso chinês e como a China conseguiu aprimorar suas políticas públicas na área educacional a partir de seus erros históricos, usando com sabedoria a combinação de programas gradualistas e focados na resolução dos problemas exsurgentes em cada etapa de seu processo de desenvolvimento. Após revolucionar a educação básica, universalizando o ensino e erradicando o analfabetismo, a China se concentra em melhorar a qualidade do ensino, dobrando o número de chineses com acesso à universidade e investindo fortemente em pesquisa, ciência e tecnologia. Desta forma, a educação e a pesquisa tecnológica são atualmente uma das principais peças de sustentação do modelo de desenvolvimento chinês no século XXI e um de seus principais "segredos de polichinelo" rumo ao progresso.

Palavras-chave: Educação, Ciência e Tecnologia. Prioridade. Políticas Públicas. Desenvolvimento Chinês.

\begin{abstract}
The purpose of this article is to describe and demonstrate how China has prioritized investment in basic and advanced education and in science and technology as strategic instruments to leverage the realization of the right to development. The problem that we are going to investigate is the indispensability of the primacy to the basic and advanced educational investments and in technological research as gradual elements of sustainability of the continuity of the Chinese progress. The methodology that we will adopt will be the one of bibliographical research. The object is scientifically relevant because it reveals how education and research in science and technology have become irreplaceable pillars for China's paradigmatic progress and how China has been able to improve its public policy in education from its historical mistakes, wisely using combination of gradualist programs focused on solving exsurgent problems at each stage of its development process. After revolutionizing basic education, universalising education and eradicating illiteracy, China focuses on improving the quality of teaching, doubling the number of Chinese with access to university and investing heavily in research, science and technology.

\footnotetext{
* Mestre em Direito (Direito e Desenvolvimento) pela Universidade Federal do Ceará (20oo). Atualmente é professor titular da Universidade do Extremo Sul Catarinense, professor do Centro Universitário de Brasília e advogado da união de categoria especial advocacia-geral da união. Doutorando do Curso de Doutorado em Direito do Uniceub. E-mail: muriack@yahoo.com

** Doutor e Mestre em Filosofia do Direito e do Estado pela Pontifica Universidade Católica de São Paulo (PUC/SP). Pós-Graduação em Filosofia e Bacharel em Direito pela Universidade Estadual de Londrina (PR). Professor Visitante na Faculdade de Direito da Califórnia, Berkeley (EUA). Professor Pesquisador Visitante no Instituto Max-Planck de História do Direito Europeu, Frankfurt (Alemanha). Pós-doutorado em Direito Comparado na Universidade de Boston, em Direito Constitucional (PUC/RS) e em Literatura (UnB). Consultor-Geral da União (2011-2015). Procurador da Fazenda Nacional. E-mail: asmgodoy@gmail.com
} 
In this way, education and technological research are currently one of the main building blocks of the Chinese development model in the twenty-first century and one of its main "polichinelo secrets" towards progress.

Keywords: Education, Science and Technology. Priority. Public Policy. Chinese Development.

\title{
1 INTRODUÇÃO
}

O presente artigo tem por objetivo demonstrar de que forma a China há privilegiado o investimento em educação básica e avançada e em ciência e tecnologia como elemento de concreção do direito ao desenvolvimento. A prioridade ao aspecto educacional e de pesquisa evidencia uma importante diretriz chinesa para obtenção da sustentabilidade de sua impressionante ascensão como uma potência no século XXI.

O problema que iremos pesquisar é o da imprescindibilidade da primazia aos investimentos educacionais e em pesquisa tecnológica como elementos de sustentabilidade da continuidade do progresso chinês. A metodologia que iremos adotar será a de pesquisa bibliográfica. O objeto é relevante cientificamente porque revela como a educação e a pesquisa em ciência e tecnologia se transformaram em sustentáculos insubstituíveis para o paradigmático progresso chinês, aspecto nem sempre salientado nas narrativas ocidentais para a ascensão chinesa.

A China conseguiu aprimorar suas políticas públicas na área educacional a partir da superação de alguns de seus erros históricos, usando com sabedoria a combinação plural de programas gradualistas e focados na resolução dos problemas exsurgentes em cada etapa de seu processo de desenvolvimento. A educação e a pesquisa tecnológica são atualmente uma das principais peças de sustentação do modelo de desenvolvimento chinês no século XXI

$\mathrm{O}$ artigo pretende demonstrar de forma inovadora que sem os enormes investimentos em educação básica, em educação avançada e em pesquisa tecnológica, a China não teria chegado ao seu atual patamar de desenvolvimento.

\section{2 - A EDUCAÇÃO E A PESQUISA EM CIÊNCIA E TECNOLOGIA COMO ELEMENTOS IMPRESCINDÍVEIS AO DESENVOLVIMENTO CHINÊS NO SÉCULO XXI.}

A questão da educação como chave para o desenvolvimento há sido um dos elementos mais importantes do planejamento chinês. Segundo LORES,

\begin{abstract}
No último Boao Forum, o chamado Davos chinês, uma das mesas mais concorridas discutia "a armadilha da renda média". Os debatedores falavam da maldição que se abatia em países que cresceram muito graças a um êxodo rural acelerado e uma industrialização de primeira fase, mas que não conseguiam virar potências desenvolvidas - o crescimento estancava depois de terminada a urbanização. Brasil e México foram citados nominalmente. Japão e Coreia seriam os contraexemplos. Empresários e intelectuais chineses falavam da importância da inovação, da educação e de reinventar a marca "Made in China" se não quisessem cair na armadilha (LORES, 2011).
\end{abstract}

Tal passagem doutrinária acima transcrita evidencia o tamanho da relevância que se dá na China para a questão da educação, e dos investimentos em ciência, tecnologia e inovação. Seria uma das chaves para não cair na problemática político-econômica epitomada de "armadilha da renda 
média”3, na qual teriam caído o Brasil e o México (PEREIRA; VELOSO; BINGWEN, 2013), e na qual não incorreram como erro crucial o Japão e a Coréia do Sul, vistos como paradigmas positivos pelos chineses, neste quesito.

Estes países asiáticos, conseguiram também através do amplo foco prioritário em educação ultrapassar os estágios iniciais do desenvolvimento, diferente do Brasil e do México, que se estagnaram porque não conseguiram dar o salto final em busca do desenvolvimento, avançando em direção a uma renda mais elevada com uma melhor distribuição de renda e de qualidade de vida para suas respectivas populações.

É importante mencionar que a questão da educação na China vem sendo tratada e pesquisada no Ocidente com um destaque menor do que deveria, com uma atenção menor do que aquela realmente devida, é tema que merece melhor descortino, pois a questão educacional é muito mais prioritária e vista como estratégica na China do que poderia parecer à primeira vista.

De fato, observando os supedâneos da criação da China Hodierna, com a ascensão de DENG em 1978, quatro foram os eixos de "modernização" declarados: agricultura, indústria, segurança e "ciência e tecnologia". Este último eixo, por óbvio, tem pertinência com a educação, pois não existe modernização em "ciência e tecnologia" sem investimento em "educação".

É mais comum se falar nas revoluções agrícolas com o fim da planificação estatal, com o impressionante processo agudo e eficaz de industrialização da China em poucas décadas, e até na evolução dos fatores militares relacionados à ordem interna e à segurança geopolítica da China.

Pouco se trata do quanto a questão da educação foi considerada um ponto crucial da evolução civilizacional do Império do Meio e de como os investimentos em educação têm transformado de maneira importante aquele vasto país. Há pouca discussão sobre a necessidade de garantir boa educação como instrumento de evolução, desenvolvimento, prosperidade e paz (MOREIRA; GOMES, 2013).

É necessário reconhecer, inicialmente, que assiste razão ao educador alemão Jürgen-Eckardt Pleines quando afirma que o pensamento hegeliano sobre a independência humana leva à conclusão de que "a educação tem o fim de fazer do homem um ser independente, isto é, dotado de vontade livre" (PLEINES, 2010).

Este papel verdadeiramente civilizatório e libertador da educação é algo que deve ser reconhecido plenamente pelo sistema jurídico. Isso significa que a educação, seja no campo da individualidade, ou no campo da coletividade, é primordial para qualquer agrupamento humano, motivo pelo qual é evidente que a educação, seja vista como um "direito", exatamente por representar um espaço amplo de evolução para cada qual individualmente e também para o orbe social (IRIBURE; CUNHA, 2011), sendo atualmente visto o dever estatal de garantir a educação como algo ligado ao "desenvolvimento do projeto de vida" de cada indivíduo, sendo a ausência de políticas estatais eficientes um veraz "dano ao projeto de vida", dano este que deve ser evitado (HACHEM; BONAT, 2017).

$\mathrm{Na}$ China, a questão educacional sempre foi um diferencial em sua cultura, sempre foi um aspecto crucial, um espaço diferenciador na sua hierarquia social confuciana. Mas, nem mesmo o ambiente educacional escapou à inglória e insana revolução cultural maoísta dos anos sessenta e setenta do século $\mathrm{XX}$.

Como observa KISSINGER, mesmo sendo o sistema educacional da China a "espinha dorsal da ordem social chinesa", o mesmo também foi atacado durante a lamentável revolução cultural maoísta. Aulas foram suspensas "indefinidamente" para que a geração dos mais jovens pudesse deambular pela China aprendendo "a revolução fazendo a revolução" (KISSINGER, 2011).

Restou no campo educacional uma enorme lacuna e trauma destes tempos irracionais e do movimento que MAO fez alegando que pretendia evitar o "revisionismo" de sua revolução comunista e

3 "O vice-presidente da Academia de Ciências Sociais da China (Cass, na sigla em inglês), Zhao Shengxuan, afirmou que a grande missão da China no momento é evitar cair na armadilha da renda média. [...] Entre as medidas que apontou como importantes para evitar que a China permaneça apenas como país de renda média, estão o aprofundamento das reformas da economia, a busca de maior eficiência e de um crescimento baseado em tecnologia, proteção do meio ambiente e questões sociais, e a melhoria de qualidade de vida da população em aspectos como moradia, emprego e educação" (CARNEIRO, 2013). 
para impedir que na China ocorresse o mesmo que MAO criticou na antiga União Soviética: a burocracia e a hierarquia haviam sobrepujado a "ideologia", e era necessário garantir um constante fluxo de renovação no seu país, uma "revolução permanente" para atalhar o congelamento das mudanças necessárias (KISSINGER, 2011).

A educação não poderia escapar a este nível de um processo nacional de "desconstrução" e "reconstrução", que tinha por lema atacar os "Quatros Velhos" ("velhas ideias, velha cultura, velhos costumes, velhos hábitos”). O resultado desse processo foi trágico e lamentável, notadamente, no campo educacional e cultural. Professores foram perseguidos e mortos, símbolos culturais do confucionismo foram destruídos aos milhares pelo país, com escolas e universidades sendo fechadas. Houve perseguição social a qualquer "especialista" em qualquer assunto que necessitasse de alguma expertise - o conhecimento especializado e aprofundado foi visto como uma mazela e um risco para a sociedade e para a revolução pretensamente igualitária do maoísmo (KISSINGER, 2011).

Foi um período de sombras considerado "desastroso" até mesmo pelo Partido Comunista Chinês - após a morte de MAO ZEDONG. Especificamente, no campo puramente educacional, o prejuízo da revolução cultural foi intenso. Foram fechadas as escolas e as universidades em 1966.

As escolas somente retomaram um ano depois, e paulatinamente, em meio à ausência de um currículo e de enormes hesitações dos professores, que não sabiam o que poderiam e nem o que deveriam ensinar. Somente ocorreu um retorno a fluxo normal de funcionamento na educação escolar chinesa fundamental em 1969 (REZZAGHI, 2009). As universidades, por sua vez, somente foram reabertas em 1976, mesmo ano da morte de MAO Zedong.

Ainda mais equivocado sob o ponto e vista das ciências, durante o período da revolução cultural, a educação e a cultura foram utilizadas como mecanismos ideológicos de persuasão e convencimento da população a respeito do acertamento dos ditames valorativos da saga comunista na China. De forma compatível com as ideias marxistas, educação e cultura eram vistas como "superestrutura" da economia, como "reflexos" das relações econômicas, e assim também precisavam ser objeto de atuação estatal fiscalizadora, controladora e direcionadora (MADEIRA, 2014).

Apesar de todos os problemas trágicos provocados pela Revolução Cultural, o final do período educacional do governo de MAO é visto como tendo uma pequena evolução no sentido de "disseminação" e "massificação" da educação. Durante as quase três décadas do maoísmo no poder houve investimento em educação fundamental, interiorização das escolas e autorização para que as mulheres recebessem educação formal - o que antes era vedado na $\mathrm{China}^{4}$, caminhando-se assim para um lento e gradual processo de "igualação educacional", construído de forma errática em meio aos excessos e contradições da Revolução Cultural.

De qualquer modo, quando DENG começa a realizar o seu "grande salto para a frente", no final dos anos 1970, a China ainda tinha o equivalente a mais de $30 \%$ de sua população na situação de analfabetismo. Isso significava o equivalente a centenas de milhões de analfabetos, com dificuldade adicional de alfabetização face às obstativas peculiaridades linguísticas do mandarim ${ }^{5}$, uma situação completamente imprópria para um país que pretendia se transformar em uma potência global.

No entanto, entre 1980 e o início dos anos 2000, o analfabetismo diminuiu de $35 \%$ para apenas

4 "Para o economista Yasheng Huang, do MIT, a importância da educação é um dos poucos legados positivos dos 30 anos de maoísmo no país. Apesar de ter fechado as universidades entre 1966 e 1976, Mao investiu na educação fundamental, expandiu a educação para o interior e, principalmente, colocou as meninas na escola, algo que ainda lhes era negado durante o império" (LORES, 2011).

5 A alfabetização na China tem ainda uma dificuldade adicional: o mandarim não tem um alfabeto, tem "caracteres", signos construídos nos séculos passados pelos chineses para permitir que diferentes culturas locais compreendessem um mesmo tipo de linguagem. Só se considera alfabetizado quando se "memorizou" a quantidade de três mil caracteres, e isso incentiva à prática da "decoreba" e da "memorização" em detrimento da "educação cognitiva" e de análise crítica. Mas, de qualquer modo, é mais difícil alfabetizar em mandarim. Nesse sentido, LORES descreve as dificuldades adicionais do aprendizado do mandarim, verbis: "Há uma questão incontornável aí: o idioma chinês não tem um alfabeto. As crianças são consideradas alfabetizadas em torno dos 11 anos, após aprender, ou seja, memorizar cerca de 3 mil caracteres. O próprio ensino do idioma demanda a memorização ou a decoreba em lugar da educação cognitiva. Ao visitar o Instituto Confúcio, a versão chinesa do British Council ou da Alliance Française para promover a cultura e o ensino do mandarim no mundo, o próprio vice-presidente da instituição, Ma Jianfei, começou a me relatar os choques culturais entre os estudantes estrangeiros e os professores chineses pelo mundo" (LORES, 2011). 
$10 \%$ de sua população, e, incontinenti, em 2016, já correspondia a 3,5\% da população ${ }^{6}$, número baixo para os percentuais internacionais (OLIVEIRA; MOTA, 2016), e um dos mais impressionantes processos massificados de erradicação do analfabetismo de que se tem história.

Foi, de fato, uma tarefa hercúlea, mas a China Comunista conseguiu praticamente erradicar o analfabetismo em seu país. Destaca LORES que o grande "segredo" educacional chinês foi uma mudança curricular aprovada em 1986, ainda no governo de DENG, e que tornou obrigatório o ensino de "nove séries (seis básicas e três intermediárias) para todas as crianças entre 6 e 14 anos de idade" (LORES, 2006).

Tais medidas levaram a uma queda abrupta do analfabetismo em menos de vinte anos - de uma taxa de $25 \%$ em 1986 para uma taxa de 8,7\% em 2006. Priorizou-se a zona rural, onde o ensino em média durava apenas quatro anos de educação formal para as crianças, ou seja, o segredo do boom educacional chinês de alfabetização em seu povo foi uma ênfase dada ao ensino básico e não ao ensino superior, naquele estágio "inicial" de desenvolvimento.7

Houve foco também no aspecto territorial. Se decidiu investir bilhões de dólares para implementação da regra da obrigatoriedade da alfabetização e do ensino básico para todas as crianças, concentrando este investimento nas áreas mais ruralizadas e interioranas - uma verdadeira política de distribuição de justiça social e de diminuição de desigualdades sociais e regionais. Eram exatamente os locais onde se concentrava a parte mais espessa do analfabetismo e das carências educacionais, tendo a China recentemente, inclusive, lançado um novo programa estatal de inclusão digital, com disponibilização maciça de computadores e rede de internet em escolas situadas no interior território chinês, melhorando a qualidade e as condições do ensino público e básico. ${ }^{8}$

Não se pode negar que a China priorizou o tema da educação, tendo dobrado seus investimentos no setor educacional, e somente seu gasto público em "Pesquisa e Desenvolvimento" alcançou o respeitável patamar de $2 \%$ do PIB, desde $2006 .^{9}$

No entanto, é importante mencionar que apesar dos avanços elogiáveis dos chineses em educação básica e na oportunização igualitária de condições educacionais à sua população, mais recentemente, é igualmente espantoso o perfil que os chineses vêm adquirindo em seus investimentos em educação para a produção no âmbito da economia criativa, da crescente terciarização econômica e do incremento da educação avançada ${ }^{10}$, no novo momento que marca a ascensão e o desenvolvimento chinês no século XXI.

Além disso, após os investimentos iniciais em educação básica, desde o final do século XX, fizeram-se alocações financeiras portentosas no ensino superior e em pesquisa e em tecnologia, cujos

6 Segundo o IBGE, em 2016, a "Taxa de alfabetização das pessoas de 15 anos ou mais de idade atingiu o patamar de 96,4\%, enquanto a "Taxa bruta de matrículas para todos os níveis de ensino" alcançou o percentual de 75,5\%. Vide: Instituto Brasileiro de Geografia e Estatísticas - IBGE. China. Disponível em: <https://paises.ibge.gov.br/\#/pt/pais/china/info/indicadores-sociais >. Acesso em o8 de dezembro de 2017 .

7 "Na China, o governo equipou 70 mil escolas do interior com computadores e conexão por satélite, com investimentos de US $\$ 1,2$ bilhão, projeto que teve apoio da fundação beneficente mantida pelo bilionário de Hong Kong Li Ka-shing. O plano é dobrar o total de computadores até 2007" (LORES, 2006).

8 "As condições das escolas primárias mais pobres da China melhoraram de forma significativa desde o início deste ano. Estas escolas, localizadas nas zonas rurais remotas, geralmente enfrentam escassez de professores e material de ensino. As coisas mudaram graças à execução de um projeto nacional para ampliar os recursos educativos digitais para essas instituições, 64 mil no total, para o final de 2015. 'Mais de quatro milhões de crianças rurais serão beneficiados do projeto', de acordo com uma declaração emitida pelo Ministério da Educação. Equipadas com receptores, decodificadores, câmeras, televisões e projetores, as 64 mil escolas pobres poderão obter acesso ao ensino de qualidade das principais escolas nas grandes cidades. A China vem destinando mais recursos nos últimos anos para o bem-estar e a educação das crianças. Durante uma viagem realizada em fevereiro de 2015 à Província de Shaanxi, o presidente chinês, Xi Jinping, enfatizou a importância da educação e assinalou que é necessária para o desenvolvimento das zonas pobres. 'Não deixem que as crianças percam na linha de partida', disse Xi” (EMBAIXADA DA CHINA NO BRASIL, 2015).

9 "Um dos grandes chamarizes que comumente se atribuem à China é o investimento educacional. Embora não esteja entre os países em que há maior percentual de alfabetizados, o investimento público em Pesquisa e Desenvolvimento é crescente. Ele mais que dobrou em uma década, o que reflete diretamente no potencial de riqueza do país diante da especialização acadêmica e melhoria das condições de ensino em nível geral" (VALADÃO; SILVA, 2009).

10 "Com o progressivo reconhecimento por parte de autoridades governamentais da necessidade de incorporar estratégias de desenvolvimento de uma economia pós-industrial, com ênfase no setor de serviços, assiste-se, naquele país, a uma revisão de valores e de prioridades políticas, em que estão incluídos investimentos em educação e na capacitação da força de trabalho; o desenvolvimento de um regime de propriedade intelectual; a relativa abertura a influências e ideias externas, mesmo que circunscrita a alguns meios e, na medida do possível, controlada; e uma tentativa de resgate de sua diversidade e herança cultural" (MADEIRA, 2014). 
frutos podem levar a uma mudança de patamar impressionante nos próximos anos. ${ }^{11}$

De fato, datam do século XXI políticas chinesas de investimentos massivos em ciência e tecnologia e criação de expertises, justamente o contrário do que se fez na trágica revolução cultural.

No ano 200o, o quadro chinês em mão-de-obra qualificada ainda não era ideal, pois naquele ano "a China possuía 459 cientistas e engenheiros para cada milhão de habitantes, o equivalente a cerca de $10 \%$ da proporção norte-americana". Havia baixa produção científica e a estrutura existente, além de insuficiente, tinha alocação concentrada demais nas áreas de engenharias e ciências. ${ }^{12}$

Para enfrentar essa defasagem educacional de qualidade, a China optou por "uma modernização do sistema de ensino nacional", passando a incentivar a "internacionalização dos estudantes" e a feitura de "seleção das melhores universidades e instituições de pesquisa para receberem incentivos do governo" (BRANDENBURG; SAMBATTI, 2008).

Foram feitas, desta forma, induções estatais relacionadas à "importação de conteúdos, principalmente nas áreas de ciência, tecnologia, direito e administração, bem como a efetivação de programas de intercâmbio para estudantes e professores" (BRANDENBURG; SAMBATTI, 2008).

Observa LORES que "a transformação da mão de obra barata em profissionais qualificados leva tempo e demanda investimentos maciços" (LORES, 2011), e a China há procurado realizar ambos, tendo preparado com investimentos na educação do final da primeira década do século XXI os profissionais e líderes a partir de 2020. ${ }^{13}$

Em 2008, depois da crise, a China criou o programa "Mil talentos", para atrair em retorno à China "PhDs chineses que trabalham e pesquisam no exterior" (LORES, 2011).

O escopo era o de fazer regressar 2 mil profissionais em 10 anos, tendo logrado trazer 669 apenas no ano de 2009, oferecendo benefícios como "altos salários, moradia, educação para os filhos e outros privilégios", para estimular o regresso dos patrícios chineses (LORES, 2011).

Além disso, "o investimento em pesquisa e desenvolvimento deve saltar entre 1,6\% do PIB", em 2011, "para 2,5\% até 2020 "14, com o objetivo adicional de dobrar a quantidade de trabalhadores chineses com nível universitário (passando do percentual de 9,4\% em 2001 para 20\% em 2020).

Em números brutos, o investimento em pesquisa na China apenas perdia para o Japão e os Estados Unidos no início da segunda década do século XXI. O Estado chinês obrigou empresas estrangeiras a montar centros de pesquisas na própria China, mais de 1.300 foram montados até o início da década segunda década do século atual, ao mesmo tempo em que autorizou que estrangeiros pudessem chefiar as empresas estatais chinesas (LORES, 2011).

Os resultados destes investimentos e políticas públicas indutoras já se demonstram, e a China, em 2016, foi a campeã asiática em exportação de produtos de alta tecnologia, superando a Coréia do Sul e o Japão, e já estava desde 2014 como líder do ranking de exportação de tecnologia de ponta. ${ }^{15}$

11 "Cumprindo o plano orçamentário da educação estabelecido em 1997, a China é o membro dos BRICS que mais investe no ensino superior. Só na área de Pesquisa e Desenvolvimento, o investimento cresceu de U\$ 39,2 bilhões para U\$ 102 bilhões, entre 2002 e 2007. Com isso, o país conseguiu oferecer mais programas curriculares e aumentar a oferta ao ensino superior" (CHALUPE, 2015). 12 "os cientistas chineses publicavam cerca de 9 mil ensaios sobre ciência e tecnologia por ano, contra 166 mil elaborados pelos acadêmicos norte-americanos", estando excessivamente concentrados os chineses do ensino superior nas áreas de engenharia e ciências (43\% dos alunos do ensino superior), o dobro dos estudantes estadunidenses nesse período concentrados em engenharias e ciências no ensino superior" (BRANDENBURG; SAMBATTI, 20o8).

13 "A educação que os estudantes chineses recebem hoje poderá ter uma forte influência sobre a maneira como o país será liderado já em 2020, quando a atual geração de estudantes começar a alcançar postos de liderança no país. Os estudantes da China de hoje têm uma formação muito mais aberta do que a que seus pais receberam. A maioria começa a estudar inglês desde cedo, e é cada vez maior o número de estudantes chineses participando de programas de intercâmbio no exterior. A tecnologia também ajuda nessa tendência. A China tem hoje o maior número de internautas do mundo e, apesar dos controles da censura, a rede permite aos estudantes estar em contato com o que acontece no resto do mundo" WASSERMAN, 2009).

14 Entre 2006 e 2012, o investimento chinês em "Investigação científica e serviços tecnológicos integrados" quintuplicou (MONTEIRO, 2015).

15 "Segundo um relatório publicado recentemente pelo Banco de Desenvolvimento da Ásia, em 2014 a exportação chinesa de produtos de alta tecnologia liderou o ranking da Ásia e representou 43,7\% de todos os produtos asiáticos deste setor, um crescimento surpreendente comparando com a cifra de 2000 , que foi de 9,4\%. Os produtos chineses de alta tecnologia, representados pelas ferrovias de alta velocidade, energia nuclear e satélites, foram aplaudidos em diversos países. Ainda segundo o relatório, em 2014 a China se tornou o principal país do continente em exportação de tecnologia de ponta. Sendo que o percentual do Japão neste setor caiu de 25,5\% em 2000 para 7,7\% em 2014, ficando atrás também da Coreia do Sul com 9,4\%. Para promover a inovação e o 
Importante, ainda, frisar o que poderia ser denominado de "nova cultura permeada de educação". Uma maneira racionalizada de debater os problemas do país e das comunidades regionais e locais. As mais importantes decisões chinesas sobre políticas públicas são debatidas com base em pesquisas produzidas pelos cientistas chinesas, e há hoje um crescente interesse da população chinesa em aprender cada vez mais, e se aperfeiçoando e se aprimorando em questões cada vez mais complexas (LORES, 2014).

Temas como o desenvolvimento de alternativas energéticas ambientalmente corretas $^{16}$ e até ferramentas hodiernas e complexas de nanotecnologia ${ }^{17}$, levaram à criação cada vez maior dos "especialistas" que a revolução cultural perseguiu há meio século, embora ainda existam problemas ${ }^{18}$ que necessitam de soluções que virão ao longo do tempo. ${ }^{19}$

Além disso, após a crise de 2008, a China voltou a se concentrar nos cuidados com a educação básica, permitindo que crianças em situação mais precária obtivessem educação dos módulos iniciais obrigatórios sem qualquer cobrança de taxas e com o recebimento de material didático fornecido gratuitamente. ${ }^{20}$

De qualquer modo, apesar dos percalços, o progresso da China no campo educacional é evidente e inegável. Da "involução do saber" da Revolução Cultural Maoísta à Revolução Tecnológica, Científica e Educacional da segunda metade do século XXI, transcorreram apenas 50 anos, o que gera maior perplexidade com o milagre chinês na área.

A questão da educação foi crucial para o desenvolvimento de uma tecnologia de ponta, de uma produção de vanguarda e de um novo país, hodierno, cientificamente alvissareiro e, em breve, colhedor de recordes em várias áreas de pesquisas que antes eram dominadas pelo Ocidente.

Por mais obnubilada que seja, a questão da educação na China é essencial para compreender a chave de seu sucesso. As políticas adotadas pelo governo chinês combinaram medidas estatais pragmáticas com o uso inteligente de medidas "liberais".

Obrigou-se o ensino e a alfabetização de milhões de chineses, mormente, no interior do país. Condicionaram-se investimentos estrangeiros à construção de centros de pesquisas tecnológicas. Enviaram-se milhares de estudantes ao exterior, com o apoio firme do Estado. Conceberam-se e desenvolvimento da manufatura chinesa, o país lançou o plano de ação Manufatura da China 2025, definindo a indústria de alta tecnologia, como a de robótica e de automóveis de nova energia, além de outros oito setores, como as prioridades no desenvolvimento industrial da China" (RÁDIO INTERNACIONAL DA CHINA, 2016)

16 "Na raiz dessa situação, está o fato de que, nos EUA, uma bem oleada coalizão de ideólogos conservadores e companhias energéticas vêm dificultando, sistematicamente, a introdução e implementação de políticas de proteção do meio ambiente. Na China, enquanto isso, os governantes da Quarta Geração têm-se notabilizado pela aplicação de medidas práticas com vistas, precisamente, ao uso mais eficiente da energia e a transição para energias verdes. Levados pela convicção de que a construção acelerada de um moderno setor de energias renováveis é, hoje, caminho eficaz para a criação de empregos e a desejada elevação do nível de vida da população" (OLIVEIRA, 2011).

17 "Xun Liu et al fizeram um estudo dos tópicos em nanotecnologia que mais apareceram nas publicações de revistas do SCI por pesquisadores chineses. As cinco palavras-chave que mais apareceram no período de 1976 a 2007 foram: (1) Microscopia de Transmissão Eletrônica (TEM), (2) Microscopia de Força Atômica (AFM), (3) Filmes Finos, (4) Nanotubos de Carbono e (5) Microscopia Eletrônica de Varredura (SEM)" (FAZZIO, 2011).

18 Como observa FLORES Jr, verbis: "Na área da educação superior, levantam-se suspeitas ou mesmo acusações de corrupção; excessivo intervencionismo político no ensino e na pesquisa; excesso de plágio; e um extremo favorecimento à quantidade e à sua rápida expansão, em forte detrimento da qualidade. Essas e outras críticas, porém, não empanam o êxito fenomenal alcançado, que justifica, a meu ver, a conotação dos tempos de hoje como uma Era Magnífica (shengshi), conceito usado pelos círculos oficiais" (FLORES Júnior, Renato G. Brasil-China: políticas de ciência e tecnologia, diferenças e desafios. In: Brasil e China no reordenamento das relações internacionais: desafios e oportunidades. Brasília: Fundação Alexandre de Gusmão, 2011. Pg. 499).

19 "Sendo a China a verdadeira terra de contrastes, a desonestidade acadêmica convive lado a lado com os inovadores. Casos de plágio de teses, dissertações e textos acadêmicos são comuns e discutidos até em publicações universitárias. Nepotismo e a influência do partido ainda superam a meritocracia em diversas universidades. E a cultura da memorização e da cópia, que vem desde que o chinês é alfabetizado em um idioma sem alfabeto, ainda colocam em dúvida a capacidade de criação autêntica do país. A aprendizagem tailor-made da New Oriental não é exceção.[...] Apesar da explosão de patentes e de papers publicados no país, muitos têm as mesmas carências dos alunos que têm ótimas notas graças ao método New Oriental. Para o pesquisador Cong Cao, do Instituto Levin, da Universidade do Estado de Nova York, a qualidade da maioria dos papers não é alta. 'A cultura tradicional confuciana, hierárquica, não permite desafiar a autoridade. Mas se há algo necessário para se avançar nas ciências, é o desafio a autoridade, ao já sabido. É o não obedecer cegamente o mentor'. (LORES, 2011).

20 "Com a crise financeira, o governo chinês também tem tomado medidas relativas à educação obrigatória que atraem muita atenção. Desde o outono de 2008, os alunos cursando a fase de ensino obrigatório em escolas públicas estão isentos de pagamentos, e aqueles oriundos de famílias di bao urbanas recebem os livros didáticos gratuitamente. A acomodação e as despesas de alunos de famílias com dificuldades financeiras são subsidiadas. Os filhos de migrantes que atendam aos critérios de admissão locais devem ser encaminhados à escola pública mais próxima e são isentos do pagamento de qualquer taxa" (FANG, Cai. Et alii, 2009). 
executaram-se programas de indução de repatriação de investidores e pesquisadores chineses já formados no exterior (estima-se que mais de um milhão e meio de chineses foram estudar no exterior nas últimas três décadas) - os "haigui" ${ }^{11}$. Concentrou-se o país inicialmente em igualar as oportunidades educacionais e depois em aprofundar-se na especialização e na educação avançada e em pesquisa e tecnologia.

Autorizaram-se estrangeiros a trabalhar em empresas estatais e em universidades chinesas, atraindo trabalhadores e pesquisadores amplamente qualificados. Chegaram "experts" estrangeiros atraídos por salários e pela fama que o país começa a ter de ser uma nova fronteira do saber, até mesmo, no que tange à construção e inauguração de bibliotecas públicas de última tecnologia, arquitetura e estética como um chamariz publicitário do conhecimento. ${ }^{22}$

Como assinala MADEIRA, todo o empenho, investimento e denodo do governo chinês e de seu povo ao tema da educação, pesquisa e tecnologia sugerem que "a pretensão é ensejar uma verdadeira virada ou renascimento cultural, ou, como sugerem alguns títulos consultados, a próxima revolução cultural ou o novo grande salto adiante" (MADEIRA, 2014).

Este novo salto adiante viria desta vez através da qualidade da produção de bens econômicos e na apresentação de novas fórmulas e novas tecnologias. É a educação e o foco em ciência e tecnologia que poderão levar a China a dar mais um passo gigantesco em sua meteórica e impressionante ascensão econômica, política e geoestratégica como potência global, se tornando novamente uma referência mundial no campo do conhecimento.

Enfim, apesar do conhecido adágio popular chinês no sentido de que "só um tolo pode prever o futuro", resta evidente que a China tem se preparado com bastante prumo para os futuros tempos ${ }^{23}$. Não parece precipitado afirmar que é através da educação e da ciência e tecnologia que a China já está se preparando para chegar ao século XXII da melhor forma possível.

Aliás, já nem se pode mais falar atualmente que a China "será" um país desenvolvido, uma vez que todos os seus predicados a tornam um grande player global no nosso presente, e que é inclusive inadequado falar em "país emergente" diante do atual estágio de progresso e prosperidade que a China já alcançou - a segunda maior economia do mundo e em crescimento contínuo e firme.

A ascensão talvez tenha sido mais rápida do que DENG e os reformistas dos anos 1970 imaginaram, e sem prejuízo desse desenvolvimento prosseguir e se complementar, pois no século XXI novas políticas

21 "Among all overseas returnees, one group that stands out consists of Chinese entrepreneurs who have launched their own businesses after studying in the West. Armed with experience working at multinational corporations (MNCs), they seized the unique growth opportunities in a reformed China to start their own enterprises. (...) These business leaders have reshaped the country's economic landscape and begun to play a more active role on the social and political stages. As agents of change, they will have a significant impact on China and the rest of the world in years to come. Haigui, a pun on haiwai guilai, meaning 'returning from overseas' (Wang, 2005), is a very popular term in China today. Its pronunciation also suggests the Chinese phrase for sea turtles returning to shore after leaving to grow up in the sea. To most people in the Western world, the notion of "returnees" is a foreign concept. In the US, Canada, Europe and Australia, a person who studies abroad almost always returns to the home country. However, for students from large developing countries such as China and India, this is not always the case. Out of more than one and one half million Chinese who went abroad during the last three decades, between two-thirds to three-quarters decided to settle in the countries where they studied, a simple fact that makes the subject of this book much more striking. However, in recent years, both the number and the rate of returnees have steadily increased. As one of the fastest growing economies in the world, China provides unprecedented opportunities to overseas returnees, who are increasingly recognized as a driving force in the country's economic development" (WANG, 2011).

22 "A cidade de Tianjin na China tem uma biblioteca nova de fazer inveja a qualquer outra. A construção deste edifício inseriu-se no projeto de um centro cultural local com mais quatro edifícios. Os arquitetos responsáveis são a MVRDV que fizeram parceria com o Instituto de Design e Planeamento Urbano de Tianjin. A construção inspirou-se no mar, com ondas de livros que emergem do piso ao topo do edifício. No centro da Biblioteca está um globo que determina todo o design à volta. As estantes dispostas de forma a parecerem ondas de conhecimento albergam 1,2 milhões de livros e são também cadeiras e degraus para aceder aos cinco níveis de construção. Com $33.700 \mathrm{~m}^{2}$, o centro cultural abriu em Outubro deste ano e já é uma das principais atrações da cidade. A construção dos cinco edifícios demorou três anos" (ROSA, 2017).

23 "Há um provérbio chinês que diz: 'Só um tolo pode prever o futuro'. Ao procurar depoimentos de previsões futuristas ao final do século XIX, início do século XX pode parecer que o provérbio chinês seja uma verdade. Há exemplos, Charles H. Duell - Chefe do Escritório de Patentes dos Estados Unidos que afirmou em 1899: ‘Tudo que poderia ser inventado já foi inventado'. O Diretor Chefe da IBM, Thomas Watson disse em 1943: 'Eu penso que no mundo não há mercado para mais que cinco computadores'. O Jornal New York Times publicou, em 1903, um artigo criticando o cientista Robert Goddart que pesquisava sobre foguetes, dizendo que seu trabalho não fazia sentido, pois 'foguetes não podem se mover no vácuo'. Hoje, fazer predições não é parte da literatura de ficção científica, é preparar-se para o futuro. O conhecimento científico acumulado nos últimos 100 anos é maior que toda história da humanidade antepassada. Há atualmente um conhecimento profundo das leis da natureza, como atuam na física, na química e na biologia. Nota-se que os chineses não são tolos e estão se preparando para o futuro" (FAZZIO, 2011). 
e prioridades foram adotadas. A China empreendeu e executou impressionante sistema com foco na educação, ciência e tecnologia, auxiliando de forma evidente o caminho para o desenvolvimento chinês que já resta praticamente delineado e encaminhado.

Este "salto desenvolvimentista" irreversível parece prestes a ser consolidado, e no caso da China é apenas a restauração de um espaço que foi perdido após um passado glorioso. E nesse caminho do desenvolvimento chinês, a prioridade nas diversificadas políticas educacionais foi um aspecto crucial e nem sempre reconhecido, legando um modelo que pode servir de paradigma para outros países que ainda precisam encontrar seus próprios caminhos em busca do desenvolvimento.

\section{CONSIDERAÇÕES FINAIS}

Se a China está prestes a se tornar uma potência global mundial plenamente desenvolvida, com planejamento e organização de sua prosperidade, deve-se reconhecer que muito contribuíram os investimentos maciços e muito bem direcionados para a educação.

Por caminhos transversos e contraditórios, a revolução cultural maoísta permitiu o acesso básico à educação às mulheres e a segmentos populacionais interiorizados que não tinham este acesso - e mesmo assim os estertores do período maoísta legou um país em que quase um terço da enorme população padecia do analfabetismo absoluto.

Com as reformas de DENG no final dos anos 7o do século XX, obrigou-se o ensino e a alfabetização de milhões de chineses, mormente, no interior do país e ainda se fez uma reforma educacional em 1986 que estipulou um parcial dever estatal de custeio e garantia da educação ${ }^{24}$, com no mínimo seis "séries" básicas e três séries "intermediárias" a todos os chineses, o que permitiu chegar aos anos 2000 com o analfabetismo abaixo de um dígito e propiciando que em 2016 o percentual de analfabetismo fosse de somente 3,6\% de sua enorme população - percentual baixo para os padrões mundiais.

Concomitantemente, e já se preparando para a continuidade de sua "revolução educacional em busca do desenvolvimento", a China ao longo do tempo condicionou os investimentos estrangeiros à construção de centros de pesquisas tecnológicas, enviou milhares de estudantes ao exterior, com o apoio firme do Estado, concebeu e executou programas de indução de repatriação de investidores e pesquisadores chineses já formados no exterior, e, mais recentemente, ainda preocupada com os resíduos de má educação em regiões menos prósperas e com indivíduos retirados do sistema de ensino, adotou políticas de melhoria da qualidade do ensino em regiões rurais e assegurou acesso educacional a segmentos populacionais em regiões mais prósperas.

Concentrou-se o país inicialmente em igualar as oportunidades educacionais na educação básica e depois em aprofundar-se na especialização e na educação avançada e em pesquisa e tecnologia superior e avançada, estimando-se que entre 2010 e 2020 a China terá conseguido dobrar o número de chineses com educação superior, completando todo um ciclo virtuoso de treinamento e preparo profissional de sua população, o que é um processo demorado e que não se obtém com improvisos e ausência de planejamento, mas, opostamente, com a implementação gradual e racional de medidas adequadas e detalhadamente programadas e executadas.

A busca da implementação da meritocracia, a procura coletiva do aprimoramento, a aposta na qualidade e na obtenção de bons resultados ${ }^{25}$, e a tenacidade em obter a concretização das metas previamente estabelecidas são marcas importantes na política educacional chinesa.

24 "Na China, só os níveis compulsórios de ensino - do primeiro ao nono ano - são gratuitos. Os três anos de ensino médio são pagos, mesmo nas escolas públicas. E mesmo nos níveis gratuitos os pais devem pagar uniforme, transporte e alimentação. O estado dá apenas os livros" (REVISTA VEJA, 2011).

25 "No último levantamento do programa internacional de avaliação de alunos da OCDE, conhecido pela sigla Pisa e divulgado no começo de dezembro, os chineses, representados por adolescentes de Xangai, foram os melhores colocados entre estudantes de 65 países nas três áreas avaliadas: ciências, leitura e matemática. Surpreendeu os técnicos da OCDE o fato de que todas as escolas chinesas avaliadas tiveram um bom desempenho - tanto as das regiões mais ricas quanto as das mais pobres. O motivo é uma lição para os responsáveis pela educação no Brasil. Em Xangai, os melhores professores costumam ser deslocados para os colégios com 
Se nos anos 8o do século XX as metas eram relacionadas à obtenção da universalização do ensino, à erradicação do analfabetismo e ao aumento do número de anos do seu sistema educacional, as metas mais recentes se relacionam à pesquisa científica avançada e à melhoria no sistema universitário - como a meta de obter-se a criação de ao menos 100 Universidades de padrão Internacional. Os objetivos são cuidadosamente estipulados e planejados para serem cumpridos rigorosamente, evitando-se metas irreais ou meramente retóricas. ${ }^{26}$

Os enormes progressos em ciência e tecnologia também estão transformando a China em uma potência mundial na área da ciência e do conhecimento, permitindo que a China saísse do papel de enorme fábrica mundial de produção industrial com uso de mão de obra intensiva para grande exportadora de bens com tecnologia avançada, superando recentemente neste item até mesmo o Japão e a Coréia do Sul, que serviram de paradigma positivo para a China no início de seu processo atual de desenvolvimento.

Os enormes avanços na área educacional se tornaram essenciais para o novo "salto adiante" que o Império do Meio está empreendendo silenciosamente nesta segunda década do século XXI, rumo ao resgate definitivo de seu papel histórico de protagonista no caminho das grandes civilizações humanas. ${ }^{27}$

Que sua prioridade ao campo da educação e das ciências se transforme em um exemplo positivo para outras nações emergentes que aspiram obter o seu próprio desenvolvimento. Os seus bons caminhos também servem para inspirar e auxiliar as jornadas de outras civilizações em busca do seu próprio desenvolvimento.

A maneira eficiente e priorizada com que a China tem tratado o tema da educação é um de seus "segredos de Polichinelo", pois se trata de assunto que é transparentemente relevante no sistema chinês, embora curiosamente o Ocidente tenha dado historicamente pouca atenção ao sucesso educacional na narrativa da sua impressionante ascensão.

\section{REFERÊNCIAS:}

BRANDENBURG, Augusto Cezar; SAMBATTI, Andréia Polizeli. Discussão dos determinantes do investimento externo direto na CHINA a partir dos anos 1990. Unioeste - Ciências Sociais em Perspectiva, n. 7, p. 77-78, 2008. Disponível em: <http://erevista.unioeste.br/index.php/ccsaemperspectiva/article/ viewFile/2565/1957>. Acesso em: 06 dez. 2017.

CARNEIRO, Luciano. China: a missão de evitar a 'armadilha da renda média'. O Globo, nov/2013. Disponível em: <https://oglobo.globo.com/economia/china-missao-de-evitar-armadilha-da-rendamedia-1085519o\#ixzz5oyqnA6nu>. Acesso em: 11 dez. 2017.

as piores notas. A própria OCDE reconhece as limitações do levantamento, feito somente em uma cidade, ainda por cima a mais rica do país. Não dá para tomar a situação de Xangai como sinônimo do que ocorre em toda a China. Mas vale lembrar que, caso São Paulo ou qualquer outra capital representasse o Brasil, o país não chegaria nem perto dos primeiros lugares. 'A China tem problemas na área da educação, sim, mas está progredindo rapidamente', diz Andreas Schleicher, diretor da OCDE responsável pela pesquisa” (REVISTA EXAME; DYER, Geoff, 2011).

26 "Os chineses aprendem que conhecimento não tem pátria nem bandeira. Importante também é a formação constante que a educação chinesa dá a todos os seus profissionais. Além do sistema de grupos de estudo de professores, em Xangai há também treinamento compulsório, todo ano, ministrado pelo governo local: uma semana em tempo integral nas férias de verão e dois dias nas férias de inverno. Em relação a diretores é a mesma coisa: ainda que o sujeito seja um grande professor, para ser efetivado precisa fazer um curso de administração escolar. Até os burocratas são constantemente estimulados a passar temporadas em universidades chinesas e do exterior. O sistema confia no talento e esforço de seus profissionais, mas não permite que o sistema dependa apenas da vontade individual. O trabalho é institucionalizado. Outra característica importante abrange o planejamento de longo prazo e a capacidade de cumprir as metas estabelecidas. O governo chinês vem criando desde a década de 8o, planos de horizonte de tempo longo (dez anos ou mais) para o seu sistema educacional. Os mais antigos versavam sobre universalização do acesso à escola e erradicação do analfabetismo. Os mais recentes falam da criação de 100 universidades de nível internacional. A grande maioria é cumprida e sua elaboração é feita de forma cuidadosa justamente para que seja cumprida. Foi curioso conversar com um dos diretores do ministério porque ele se referia aos números dos planos - cada um é identificado por três ou quatro algarismos como os projetos de lei brasileiros - da mesma forma que um pastor evangélico cita capítulos e versículos da Bíblia: como se aquilo fosse um axioma, e conhecido por todos" (REVISTA DIGITAL, 2012).

27 "O resto do mundo esfrega os olhos estupefato. Em menos de três décadas, a China cresceu de um miserável país em desenvolvimento a um gigante da economia mundial. Agora, trabalha para se tornar uma potência global” (DEUTSCHE WELLE, 2018). 
CHALUPE, Samil. Apesar do Investimento, ensino superior na China tem obstáculos, out./2015. ABC. Disponível em: <http://www.abc.org.br/article.php3?id_article=4415>. Acesso em: o8 dez. 2017.

DEUTSCHE WELLE. XI Jinping e o Sonho Chinês, mai./2018. Disponível em: <http://www.dw.com/ptbr/xi-jinping-e-o-sonho-chin\%C3\%AAs/a-43686076>. Acesso em: o7 mai. 2018.

DYER, Geoff. A China Faz a Lição de Casa, fev./2011. Revista Exame. Disponível em: <https://exame.abril. com.br/revista-exame/a-china-faz-a-licao-de-casa/>. Acesso em: 31 mar. 2018.

EMBAIXADA DA CHINA NO BRASIL. China investe pesado na educação das crianças, jun./2015. Disponível em: <http://br.chinaembassy.org/por/szxw/t126913o.htm>. Acesso em: o8 dez. 2017.

FAZZIO, Adalberto. Brasil e China Juntos no Futuro da Nanotecnologia. In: Brasil e China no reordenamento das relações internacionais: desafios e oportunidades. Brasília: Fundação Alexandre de Gusmão, 2011.

FLORES Júnior, Renato G. Brasil-China: políticas de ciência e tecnologia, diferenças e desafios. In: Brasil e China no reordenamento das relações internacionais: desafios e oportunidades. Brasília: Fundação Alexandre de Gusmão, 2011.

HACHEM, Daniel Wunder; BONAT, Alan. O Direito ao Desenvolvimento de um Projeto de Vida na Jurisprudência da Corte Interamericana de Direitos Humanos e a Educação como Elemento Indispensável. Revista Opinião Jurídica, Fortaleza, ano 15, n. 21, p.77-105, jul./dez. 2017.

INSTITUTO BRASILEIRO DE GEOGRAFIA E ESTATÍSTICAS - IBGE. China. Disponível em: <https:// paises.ibge.gov.br/\#/pt/pais/china/info/indicadores-sociais>. Acesso em: o8 dez. 2017.

IRIBURE, Júnior; CUNHA, Hamilton da. Direito à Educação: uma questão de justiça social. Revista "Direito e Desenvolvimento", João Pessoa, v. 7, n. 2, p. 77-95, 2011.

KISSINGER, Henry. Sobre a China. Tradução de Cássio de Arantes Leite. Rio de Janeiro: Objetiva, 2011.

LORES, Raul Juste. Um novo modelo de desenvolvimento Brasil - China. In: Brasil e China no reordenamento das relações internacionais: desafios e oportunidades. Brasília: Fundação Alexandre de Gusmão, 2011.

. Revolução na Escola - China investe no ensino básico e Índia aposta em elite universitária. Folha de São Paulo, jul./2006. Disponível em: <http://wwwi.folha.uol.com.br/fsp/especial/fi3007200610. htm>. Acesso em: o7 dez. 2017.

MADEIRA, Mariana Gonçalves. Economia criativa: implicações e desafios para a política externa brasileira. Brasília: FUNAG, 2014.

MONTEIRO, Solange. Distintas demandas. Revista Conjuntura Econômica, Rio de Janeiro, v. 69, n. 10, p. 64-65, out./2015. Disponível em: <http://bibliotecadigital.fgv.br/ojs/index.php/rce/article/ view/59525/57894>. Acesso em: 07 dez. 2017.

MOREIRA, VITAL e GOMES, Carla de Marcelino (coord.). Compreender os Direitos Humanos - manual de educação para os direitos humanos. 3. ed. Lisboa: Ius Gentium Conimbrigae/Centro de Direitos Humanos Faculdade de Direito da Universidade de Coimbra (FDUC), 2013. 
OLIVEIRA, Amaury Porto de. Brasil-China: Buscar Convergência nas TE. In: Brasil e China no reordenamento das relações internacionais: desafios e oportunidades. Brasília: Fundação Alexandre de Gusmão, 2011.

OLIVEIRA, Marcos Fábio Martins de; MOTA, Sarah Dantas Rabelo. Desenvolvimento econômico na china pós 1978: análise das vocações desenvolvimentista e social. Anais do V Congresso de Desenvolvimento Social - Estado, Meio Ambiente e Desenvolvimento, jun/jul. 2016. Disponível em: <http://www. congressods.com.br/anais/gt_11/DESENVOLVIMENTO\%2oECONOMICO\%2oNA\%2oCHINA\%20 POS\%201978.pdf>. Acesso em: o7 dez. 2017.

PEREIRA, Lia Valls; VELOSO, Fernando; BINGWEN, Zheng (org). Armadilha da Renda Média: visões do Brasil e da China. vol. o1-02. Rio de Janeiro: Fundação Getúlio Vargas - FGV Editora, 2013.

PLEINES, Jürgen-Eckardt. Friedrich Hegel. Sílvio Rosa Filho (org.). Recife: Fundação Joaquim Nabuco, Editora Massangana, 2010. Disponível em: <http://www.dominiopublico.gov.br/download/texto/me4671. pdf>. Acesso em: 07 mai. 2018.

RÁDIO INTERNACIONAL DA CHINA. China é o Maior Exportador de Tecnologia de Ponta da Ásia. Tradução de Xia Ren e Revisão de Denise Melo, jan./2016. Disponível em: <http://portuguese.cri. cn/1721/2016/o1/o6/1s210419.htm:>. Acesso em: o7 dez. 2017.

REVISTA DIGITAL. O Que Podemos Copiar da Educação Chinesa? Mar/2012. Disponível em: <http:// www.revistadigital.com.br/2012/03/o-que-podemos-copiar-da-educacao-chinesa/>. Acesso em: 31 mar. 2018.

REVISTA VEJA. O Sistema Educacional que Fez da China uma Potência. Dez./2011. Disponível em: < https://veja.abril.com.br/educacao/o-sistema-educacional-que-fez-da-china-uma-potencia/>. Acesso em: 31 mar. 2018.

REZZAGHI, Mariana Delgado Barbieri. A Educação no Período de Transição Socialista: a experiência chinesa da Revolução Cultural e as mudanças no ensino e nas relações de produção. Campinas, SP: Unicamp, [s. n.], 2009.

ROSA, Joana. Biblioteca na China Inspirou-se no Mar e o Resultado é Surreal - Ondas de livros representam o oceano de conhecimento. Asckmen, nov./2017. Disponível em: <http://pt.askmen.com/entertainmentnews/2485/article/biblioteca-na-china-inspirou-se-no-mar-e-o-resultado-e-surre >. Acesso em: o7 dez. 2017 .

VALADÃO, Marcos Aurélio Pereira; SILVA, Lauriana Magalhães. Economia chinesa: evolução e tendências. Revista do Mestrado em Direito da UCB. v. 03, n. 02, 2009.

WANG, Huiyao. Chinese Returnees, a Globalization Force in Changing Modern China, April/2011. SSRN. Disponível em: <https://ssrn.com/abstract=1976774>. Acesso em: 11 dez. 2017.

WASSERMAN, Rogerio. China Moderniza Educação para Garantir Liderança Econômica. Publicado em 02 de abril de 2009. BBC BRASIL. Disponível em: <http://www.bbc.com/portuguese/ noticias/2009/04/090402_china_modernizacao>. Acesso em: 05 abr. 2018. 